\title{
The more the better ... or is it? The contradictory effects of HR practices on knowledge-sharing motivation and behaviour
}

Tatiana Andreeva*, Maynooth University, School of Business,

St. Petersburg University Graduate School of Management

Anastasia Sergeeva*, VU University Amsterdam, Faculty of Economics and

Business Administration

Human Resource Management Journal, Vol 26, no 2, 2016, pages 151-171

This article examines how individual-level antecedents such as motivation and ability to share knowledge mediate the relationship between HR practices and knowledge-sharing behaviour. The results of a survey of 329 secondary school teachers reveal the contradictory effects of different HR practices on the mediating roles of intrinsic and extrinsic motivation to share knowledge and subsequent knowledge-sharing behaviour of teachers. The study demonstrates that opportunity-enhancing HR practices act as a moderating condition that activates either intrinsic or extrinsic motivation to share knowledge and may completely offset the effect of motivation-enhancing HR practices. The study makes a distinctive contribution by demonstrating how certain combinations of HR practices aimed to enhance knowledge sharing might in fact be a costly solution for organisations, as they activate different mediating mechanisms in the HRM-knowledge-sharing behaviour link.

Contact: Tatiana Andreeva, School of Business, Maynooth University, Maynooth, Co. Kildare, Ireland. Email: tatiana.andreeva@nuim.ie

Keywords: knowledge sharing; HR practices; knowledge governance; ability-motivationopportunity (AMO) framework; mediation and moderation; intrinsic and extrinsic motivation

\section{INTRODUCTION}

-

ollowing the advance of the knowledge-based view of the firm, knowledge sharing has been recognised as an important process contributing to organisational performance (Grant, 1996; Dixon, 2000; Foss et al., 2010). It spurred the debate among HRM researchers on how to foster knowledge sharing among employees through HR practices. The link between HRM and knowledge sharing has been widely explained in the theoretical literature (Jackson et al., 2006; Foss et al., 2010; Minbaeva, 2013) and addressed in a number of empirical studies (Foss et al., 2009; Reinholt et al., 2011; Kuvaas et al., 2012; Minbaeva et al., 2012; Swart and Kinnie, 2013). While these studies provide some rich insights into potential HR practices that can be used to enhance knowledge sharing, some core questions still remain unanswered.

First, we still lack a comprehensive understanding of how these HR practices bring about organisational outcomes and which mediators may intervene in this relationship. HRM research has been overly focused on distal HR outcomes, leading to gaps in understanding the mechanisms linking HR practices to performance (Jiang et al., 2012; Kehoe and Wright, 2013). The knowledge governance approach (Foss, 2007; Minbaeva et al., 2009) recently suggested that these mechanisms could be best uncovered through examining individual-level attitudes and behaviours as critical intermediaries between managerial practices and organisational

* The authors contributed equally to this work. 
performance. Several empirical studies have made progress in addressing this gap (Foss et al., 2009, 2015; Reinholt et al., 2011; Minbaeva et al., 2012). Still, a recent review of the research on HRM and knowledge sharing (Minbaeva, 2013) concludes that existing studies provide an incomplete picture because they focus either on some single HR practice aimed to promote knowledge sharing or on a single individual-level antecedent of this behaviour, and none of them address both multiple HR practices and multiple individual-level mediators. This is problematic because in reality employees are exposed simultaneously to multiple bundles of HR practices, and multiple mediation pathways may exist between them and employee behaviour (Jiang et al., 2012).

Second, little research has been carried out on the differentiated effects various HR practices may have on individual attitudes and behaviours and on the potential interactions between those (Jiang et al., 2012) - both in HRM studies in general and in knowledge-sharing research in particular. For example, some studies find that providing few opportunities for knowledge sharing can have a 'bottleneck' effect (Siemsen et al., 2008; Reinholt et al., 2011), and others find that rewards have no (Liu and Liu, 2011) or a negative impact on knowledge sharing (Bock et al., 2005). What impact do all these practices have if they are applied together? Does the effectiveness or failure of one HR practice depend on the availability of others (Kepes and Delery, 2007; Boxall et al., 2011)? Foss et al. (2015) demonstrate that several HR practices aimed to enhance intrinsic motivation to share knowledge have a stronger effect on this type of motivation when applied together, but they do not consider how intrinsic motivation mediates the further impact of HR practices on behaviour or whether other potential mediators may intervene in this relationship. If different HR practices activate different individual-level mediators, what would their total effect on behaviour look like? Summarising these concerns, Minbaeva et al. (2009) raise the question of whether implementing more practices to support knowledge sharing is always better for the organisation and call for more research on multiple HR practices and their interactions with multiple mediators.

This study addresses these gaps by exploring how individual-level antecedents mediate the relationship between HR practices and knowledge-sharing behaviour, incorporating both multiple predictors and mediators, and by examining the differentiated effects these HR practices have on employee behaviour. Our findings contribute to the knowledge perspective in HRM research by demonstrating how certain combinations of HR practices aimed to enhance knowledge sharing might in fact be a costly solution for organisations, as they activate different mediating mechanisms in the HRM-knowledge-sharing behaviour link.

\section{MEDIATED NATURE OF THE RELATIONSHIP BETWEEN KNOWLEDGE-SHARING HR PRACTICES AND INDIVIDUAL BEHAVIOURS}

Prior studies have identified an array of HR practices that impact knowledge-sharing behaviour, for example, training, job design, employee rotation and monetary bonuses (e.g. Bock et al., 2005; Cabrera et al., 2006; Jackson et al., 2006; Lin, 2007; Foss et al., 2009; Kuvaas et al., 2012; Swart and Kinnie, 2013). However, most of them focused either on one of the HR practices or on individual-level antecedents of knowledge sharing. To build a comprehensive model that conceptualises multiple elements on both levels of knowledge-sharing antecedents - that of HR practices and another of individual attributes - we build on the arguments put forward by Lepak et al. (2006) and Jiang et al. (2012). Integrating a rich body of HRM research, Lepak et al. (2006) and Jiang et al. (2012) suggest that the multitude of HR practices and elements of HR systems covered in the literature can be grouped into three main categories, that is, those enhancing employees abilities, fostering motivation and providing opportunities to 
perform. These practices are then conceptualised to influence performance indirectly by fostering two key performance antecedents at the individual employee level - ability and motivation to perform (e.g. Gardner et al., 2011; Liao et al., 2009; Takeuchi et al., 2007; Youndt and Snell, 2004). Lepak et al. (2006) also suggest that HR systems and their constituent practices should be targeted to some strategic objective. Following their logic, we focus in this article on the HR practices that are aimed at enhancing knowledge sharing in organisations. Further on, we distinguish between three groups of such HR practices, aimed respectively to enhance employee abilities to share knowledge, foster their motivation to share and provide relevant opportunities; and between motivation and ability to share knowledge as mediating individual attributes. Based on this theoretical framework in the following sections we develop our hypotheses suggesting that employee knowledge-sharing behaviour is best explained by the interplay of these HR practices and individual-level attitudes and skills.

\section{Motivation-enhancing HR practices}

Motivation-enhancing HR practices focus on influencing employee motivation to perform (Lepak et al., 2006; Jiang et al., 2012). Self-determination theory identifies two motivation types - intrinsic and extrinsic (Ryan and Connell, 1989) - and has been widely used recently to explain the motivation to share knowledge (Osterloh and Frey, 2000; Lin, 2007; Foss et al., 2009; Gagné, 2009). Distinguishing between these two types of motivation to share knowledge is essential from a HRM perspective, as they call for different HR actions.

The intrinsic motivation to share knowledge refers to the feeling of internal satisfaction and enjoyment of a person when engaging in knowledge sharing (Osterloh and Frey, 2000), and this feeling appears to be a key predictor of such behaviour (Foss et al., 2009; Reinholt et al., 2011; Kuvaas et al., 2012). The HR challenge, however, according to self-determination theory, is that intrinsic motivation arises within an individual relatively independently and resists direct and immediate external manipulation (Ryan and Connell, 1989). Recent literature has discussed a number of possible avenues to address this challenge. Building on self-determination theory (Deci and Ryan, 2004), which lists autonomy, relatedness and freedom from criticism as important antecedents of intrinsic motivation, and on job characteristics theory (Hackman and Oldham, 1976), organisation theorists argue that managers have the opportunity to elicit intrinsic motivation from their employees by exercising autonomy-supportive leadership styles and by implementing job designs that allow employee discretion and autonomy (Gagné and Deci, 2005; Gagné, 2009). Although some evidence has been accumulated on the relationship between HR practices and the intrinsic motivation of employees to perform in general (e.g. Gagné and Deci, 2005; Cerasoli et al., 2014), this argument has so far been insufficiently tested in the particular case of knowledge-sharing behaviour (an exception is Foss et al., 2009). Summarizing these arguments we hypothesise that

Hypothesis 1: Intrinsic-motivation-enhancing HR practices influence individual knowledge-sharing behaviour indirectly by increasing the intrinsic motivation to share knowledge.

Extrinsic motivation refers to the external benefits an employee associates with engaging in knowledge sharing (Foss et al., 2009) and thus seemingly lies within the direct control of managers. Discussing how to promote knowledge-sharing behaviour in organisations, the knowledge-sharing literature has widely addressed such extrinsic-motivation-enhancing HR practices as monetary bonuses, career promotion or official recognition (Bock et al., 2005; Cabrera et al., 2006; Lin, 2007) and often offered these practices as the first solution to solve 
the knowledge-sharing problem (Bartol and Srivastava, 2002). However, the existing research is inconclusive on whether they are indeed positively effective.

Empirical evidence regarding the impact of external rewards on knowledge-sharing behaviour is controversial. For example, Bock et al. (2005) find a negative effect, Lin (2007) finds no significant effect and Cabrera et al. (2006) find a positive effect of perceived rewards on knowledge sharing. Theoretical arguments used to explain these effects are also conflicting. According to self-determination theory, external rewards for knowledge sharing are expected to be detrimental to knowledge sharing by 'crowding out' intrinsic motivation (Osterloh and Frey, 2000). The idea is that on being offered external rewards, a previously intrinsically motivated person starts to perceive that his or her actions are no longer guided by internal satisfaction but rather are being pushed externally, and thus loses interest in the activity (Deci and Ryan, 2004). At the same time, other authors use the lenses of social exchange (Blau, 1964) or expectancy (Vroom, 1994) theories to argue that an individual engages in knowledge sharing after estimating the potential costs and benefits, and therefore, external rewards are theorised to affect knowledge sharing positively (Bock et al., 2005; Cabrera et al., 2006; Foss et al., 2009).

We suggest that this controversy can be partially clarified by separating the two constructs external stimuli in the form of HR practices (e.g. "my organization offers monetary bonuses for knowledge sharing') and extrinsic motivation that refers to an employee's predisposition to act (or not) based on these stimuli (e.g. 'I want to share knowledge because I will get a bonus for this') - and by viewing intrinsic and extrinsic motivation as two mediators in the relationship between the offered rewards and the resulting behaviour. For example, an organisation may offer a bonus for knowledge sharing; if an employee finds this bonus extrinsically motivating, she or he will be likely to engage in the desired behaviour. At the same time, if the bonus is perceived as irrelevant or unimportant by an employee, it will not create extrinsic motivation, and therefore, it will not lead to knowledge sharing. Moreover, such a bonus may, according to the 'crowding out' effect (Osterloh and Frey, 2000), be detrimental to the intrinsic motivation to share. Therefore, we hypothesise that

\section{Hypothesis 2: Extrinsic-motivation-enhancing HR practices influence individual knowledge-sharing behaviour indirectly by (a) increasing the extrinsic motivation to share and (b) decreasing the intrinsic motivation to share.}

\section{Ability-enhancing HR practices}

To share knowledge with colleagues, in addition to motivation, employees have to possess certain skills in order to be able to effectively explicate and transfer what they know. This view is widely supported in both the conceptual (Cohen and Levinthal, 1990; Hinds and Pfeffer, 2003) and empirical (Reinholt et al., 2011; Chang et al., 2012) knowledge-sharing studies. The literature discusses the wide array of individual characteristics as elements of the ability to share knowledge. They range from the capability to find a common language with colleagues (Nahapiet and Ghoshal, 1998) to the capability to learn and acquire new knowledge (Cohen and Levinthal, 1990) to the capability to verbalise and externalise one's own knowledge (Gavrilova and Andreeva, 2012) to having the skills to transfer knowledge to novices (Hinds and Pfeffer, 2003) and to knowledge sharing self-efficacy - a belief in one's own ability to share (Chiu et al., 2006). Therefore, ability-enhancing HR practices for knowledge sharing may include training in communication skills, self-reflection, teamwork or mentoring (Jackson et al., 2006).

In essence, these practices are meant to influence individual knowledge-sharing behaviours by improving employee abilities to share knowledge. In other words, this implies a mediated relationship. However, this is not the only path through which ability-enhancing HR practices 
may impact employee knowledge-sharing behaviour. Prior research has demonstrated that training and development may also positively impact on employee motivation (Tannenbaum et al., 1991). The literature offers two theoretical explanations for this relationship. First, training and development improve employee self-efficacy (Bandura, 1977). The latter, in turn, is claimed to be closely positively related to intrinsic motivation as it provides a satisfaction of the basic psychological need for competence (Ryan and Deci, 2000). Second, according to social exchange theory, employee development practices contribute to employee positive attitudes towards the organisation and evoke a reciprocal willingness to do their best, thus also leading to an increase in intrinsic motivation (Kuvaas et al., 2012). Based on these arguments we hypothesise that

Hypothesis 3: Ability-enhancing HR practices influence individual knowledge-sharing behaviour indirectly by increasing employee (a) ability to share knowledge and (b) intrinsic motivation to share knowledge.

\section{Opportunity-enhancing HR practices}

HRM literature suggests that even if employees have the ability to perform assigned tasks and are motivated to do so, this will not foster performance, unless organisations provide employees with appropriate opportunities to apply their skills and motivation (e.g. Lepak et al., 2006; Jiang et al., 2012). Extending this logic to the case of knowledge-sharing behaviour, such opportunity-enhancing HR practices may include organising knowledge-sharing-focused meetings and workshops; providing time at work for sharing, employee rotation, job design and workspace design that allow for teamwork and free communication; and supporting communities of practice (Dixon, 2000; Wu et al., 2007).

How do opportunity-enhancing HR practices influence employee behaviour? In knowledge-sharing studies, opportunity has been found to play a 'bottleneck' role, being both a potential catalyst and inhibitor of knowledge sharing (Siemsen et al., 2008; Reinholt et al., 2011). These studies demonstrate that when employees are both willing and able to share knowledge, provisions of relevant opportunities lead to a high degree of activity in knowledge sharing. On the other hand, when such opportunities are lacking, even motivated and skilled employees do not share knowledge. However, these studies operationalised opportunity as time availability (Siemsen et al., 2008) and network position (Reinholt et al., 2011), and thus did not measure opportunity-enhancing HR practices as such. These considerations lead us to hypothesise the moderating effect of opportunity-enhancing HR practices on knowledgesharing behaviours as follows:

Hypothesis 4: The impact of the (a) intrinsic motivation to share knowledge, (b) extrinsic motivation to share knowledge and the (c) ability to share knowledge on individual knowledge-sharing behaviour is stronger in organisations that provide more opportunity-enhancing HR practices compared with organisations that provide fewer opportunity-enhancing HR practices.

\section{METHOD}

\section{Study context}

This study focused on knowledge-sharing HR practices in 22 secondary schools in St. Petersburg, Russia. These organisations were selected because they are inherently knowledge-intensive; their main 'product' is created through the methodological and subject knowledge of teachers (Starbuck, 1992). Many educational theorists and policymakers have been arguing for enhancing knowledge sharing in schools through teacher collaboration, teacher teams and teacher professional learning communities as a means to increase school 
effectiveness and the quality of secondary education (Hargreaves and Fullan, 2012). At the same time, from a managerial point of view, encouraging teachers to share their knowledge represents a significant challenge for schools because the work of a teacher has traditionally been individual and autonomous, requiring minimum interaction with colleagues (Fullan, 2002).

In the secondary school context (at least in Russia), HR functions are carried out by school principals and their deputies. Although strategic HR policies are usually formulated at local and federal government education committee levels, school principals have some discretion in which HR practices to implement and how. For example, teachers receive standardised salaries according to the national grade system, but principals can offer additional bonuses and non-monetary rewards. When executing other HR functions, principals are relatively autonomous from governmental committees. Therefore, by HR practices that are used to enhance knowledge sharing among teachers, we mean the set of practices at the school level and exercised by the school administration team.

\section{Sample and procedures}

Data were collected using a web-administered questionnaire from the schools of one district in St. Petersburg in two rounds, in October-November 2011 and in February-March 2013. We limited our study population to one district in St. Petersburg to control for potential environmental differences. Our research was presented to the principals and managers of all 52 schools in the district, and six schools volunteered to participate in the first round of the study. This round was of an exploratory nature and involved both qualitative and quantitative research methods; most of its findings are beyond the scope of this article. Of relevance here is that one of the aims of the first round was to pilot the questionnaire that we planned to use for the second wave of the data collection. This pilot study gained 117 usable employee responses, with a response rate of 40 per cent. Later on, principals of all schools in the district, except for those six that participated in the first round, were invited to participate in the second round of the study that involved only the survey described here. Twenty-two school representatives (42.3 per cent of the total target population) agreed to provide their employees with the link to the questionnaire. The average number of employees in a school is about 50; thus, our targeted teachers' population was approximately 1100 teachers. A final sample of 329 questionnaires was returned, giving a response rate of 33.2 per cent. The theoretical model in this paper was tested with the data collected during the second wave only. Of these respondents, 94 per cent were women, 75 per cent had higher education qualifications, the dominant group was over 40 years old (69.4 per cent) and had over 15 years of experience in the profession (66 per cent).

\section{Measures}

Unless otherwise stated, responses to all questionnaire items were scored on a six-point Likerttype scale measuring respondents' agreement or disagreement with proposed statements ( $1=$ strongly disagree and $6=$ strongly agree).

Knowledge-sharing behaviour Individual knowledge-sharing behaviour was measured using a five-item scale adapted from Hsu et al. (2007).

Intrinsic and extrinsic motivation to share knowledge Two types of motivation to share knowledge were measured using a scale from the Self-regulation Questionnaire by Ryan and Connell (1989), which was adapted to knowledge-sharing behaviour by Foss et al. (2009) and Reinholt et al. (2011). 
Individual knowledge-sharing ability Various proxies were adopted in previous studies to measure this construct, such as tenure (Constant et al., 1994) or individual involvement in job rotation and training (Reinholt et al., 2011). However, such measures are problematic for two reasons. First, former studies show that employee tenure and expertise are not equal to the ability to share knowledge and might in fact act as a barrier to transferring know-how to peers (Hinds et al., 2001; Gavrilova and Andreeva, 2012). Second, measures such as involvement in the company's training overlap conceptually with measures of HR practices (e.g. training), obscuring the mediating relationships between them. Therefore, we searched for a different approach. Building on self-efficacy theory (Bandura, 1977), which suggests that a person's ability is largely determined by his or her beliefs in 'own competence', we propose to operationalise the construct of knowledge-sharing ability through a proxy of 'knowledgesharing self-efficacy'. By knowledge-sharing self-efficacy, we mean a person's confidence in his or her ability to explain his or her knowledge to colleagues, as well as to comprehend the knowledge being received from colleagues. We developed the scale for 'knowledge-sharing self-efficacy' based on Parker's (1988) scale for role-breadth self-efficacy adapting its items to knowledge sharing with colleagues.

\section{Motivation, ability, opportunity-enhancing HR practices}

The measure for extrinsic-motivation-enhancing $H R$ practices (rewards) was conceptually grounded in the literature on rewards for knowledge sharing (Bartol and Srivastava, 2002; Gagné, 2009) and based on the scale validated by Kianto et al. (2011). We adopted from this scale three items that refer to knowledge sharing, asking teachers to indicate to what extent the school provides monetary or non-monetary rewards specifically for knowledge sharing and if the school includes knowledge sharing as a component in teacher evaluations.

The measure for intrinsic-motivation-enhancing HR practices (autonomy) was based on the three-item scale validated by Foss et al. (2009). This scale is based on Hackman and Oldham's (1975) instrument for measuring job characteristics (the Job Characteristic Inventory).

The measure for ability-enhancing HR practices (training) was developed by us from the conceptual framework by Jackson et al. (2006) and theoretical considerations by Jiang et al. (2012). It included three items asking teachers to indicate to what extent their schools provided training to develop interpersonal communication skills, teamwork skills, self-reflection and knowledge-externalisation skills.

The measure for opportunity-enhancing HR practices (meetings) was based on the scale of practices of social interaction for knowledge sharing, developed and validated by $\mathrm{Wu}$ et al. (2007). We used seven items from their nine-item scale, as we had to exclude two items (labelled 'apprenticeship and coaching') as irrelevant to the study context based on the results of the qualitative stage of the research that revealed that these practices are not exercised in the schools we studied.

All the survey items are presented in Table A1 in the Appendix.

Controls Previous research has highlighted the potential relationships that might exist between knowledge sharing and demographic variables (Wang and Noe, 2010). Therefore, data were collected, and controlled for, on gender $(1=$ male, $2=$ female), age (measured as seven intervals: 20-24 years; 25-29 years; 30-34 years; 35-39 years; 40-49 years; 50-59 years; and over 60 years), education (measured as five levels roughly equivalent to the following degrees: high school; bachelor; master; two masters with different specialisations; and PhD), tenure in particular organisation (measured as seven levels: less than 1 year; $1-3$ years; $4-10$ years; 11-15 years; $16-20$ years; $21-25$ years; and over 25 years) and overall experience in the 
teaching profession (same levels as tenure). To capture the possible nested effects of the organisation, we also included schools as control variables.

\section{RESULTS}

\section{Testing the measurement model}

First of all, we conducted exploratory factor analysis, using the data from the first round of the survey. The exploratory factor analysis showed that self-efficacy fully cross-loaded on knowledge-sharing behaviour and intrinsic motivation. ${ }^{1}$ Therefore, the factor of ability to share knowledge (measured as self-efficacy) was excluded from further analysis. For this reason, we could not test our Hypotheses 3a and 4c.

Next, we moved to our main data set, collected during the second round of the project. Because the data for all of the items were collected from individual respondents, they are potentially subject to common method bias (Podsakoff et al., 2003). We addressed this potential risk through the following measures. First, we formulated the questionnaire items so that they referred to concrete practices established in organisations and the individual items were formulated as first-person statements. Second, we conducted a confirmatory factor analysis to test for the potential influence of common method bias and to ensure discriminant validity of constructs. All items were loaded onto their identified structures (seven latent factors), and this model was compared with the solution that loaded all items onto a single factor (the Harman (1976) test). The fit of the seven-factor model to the data was good $\left[\chi^{2}=505.717, \chi^{2} /\right.$ degrees of freedom $(\mathrm{df})=1.983$, Tucker-Lewis index $(\mathrm{TLI})=0.929$, comparative fit index $(\mathrm{CFI})=0.94$, root mean square error of approximation $(\mathrm{RMSEA})=0.055$ with $p>0.05$ ] (see $\mathrm{Hu}$ and Bentler (1999) for indicative levels of indexes for a good-fitting model). This model was also superior and significantly different from the one-factor solution, which produced poor statistical fit $\chi^{2}=2022.305, \chi^{2} / \mathrm{df}=7.354$, TLI $=0.544, \mathrm{CFI}=0.582$, RMSEA $=0.139$ with $p<0.001, \chi^{2}$ diff. $=1516.588$ at $\left.p<0.001\right)$. The fit indices indicate that the constructs are distinct from one another and that common method bias does not unduly influence the results. ${ }^{2}$

Several of the scale items were excluded from the scales during confirmatory factor analysis (they are indicated in Table A1 in the Appendix). Table 1 presents the means, standard deviations (SD), scale reliability measures and inter-scale correlations for the variables used for further analysis.

\section{Ability-enhancing and motivation-enhancing HR practices: testing the mediation hypotheses}

In order to test for Hypotheses 1, 2 and 3 regarding the mediated impact of HR practices on individual knowledge-sharing behaviour, full structural equation modelling (SEM) was carried out using AMOS version 21.0. We used SEM (Kline, 2011) as it allows the testing of hypotheses that include multiple simultaneous dependencies among latent variables, distinguishing between direct and indirect effects, while accounting for measurement errors of the multi-item constructs. To test for mediation effects, we followed the established approach (Baron and Kenny, 1986; Kline, 2011) and compared alternative models: fully mediated, partially mediated and a model with no mediation at all. Fit statistics for these models are presented in Table 2 (models A-D).

We first tested the model based on our theory. In particular, in accordance with our hypotheses, we set the indirect effects between rewards and knowledge-sharing behaviour (fully mediated by extrinsic motivation) and autonomy and knowledge-sharing behaviour (fully mediated by intrinsic motivation). The link between ability-enhancing practices and behaviour was set for both direct (to account for the missing variable of ability to share) and indirect (partially mediated through intrinsic motivation). The results of this analysis 


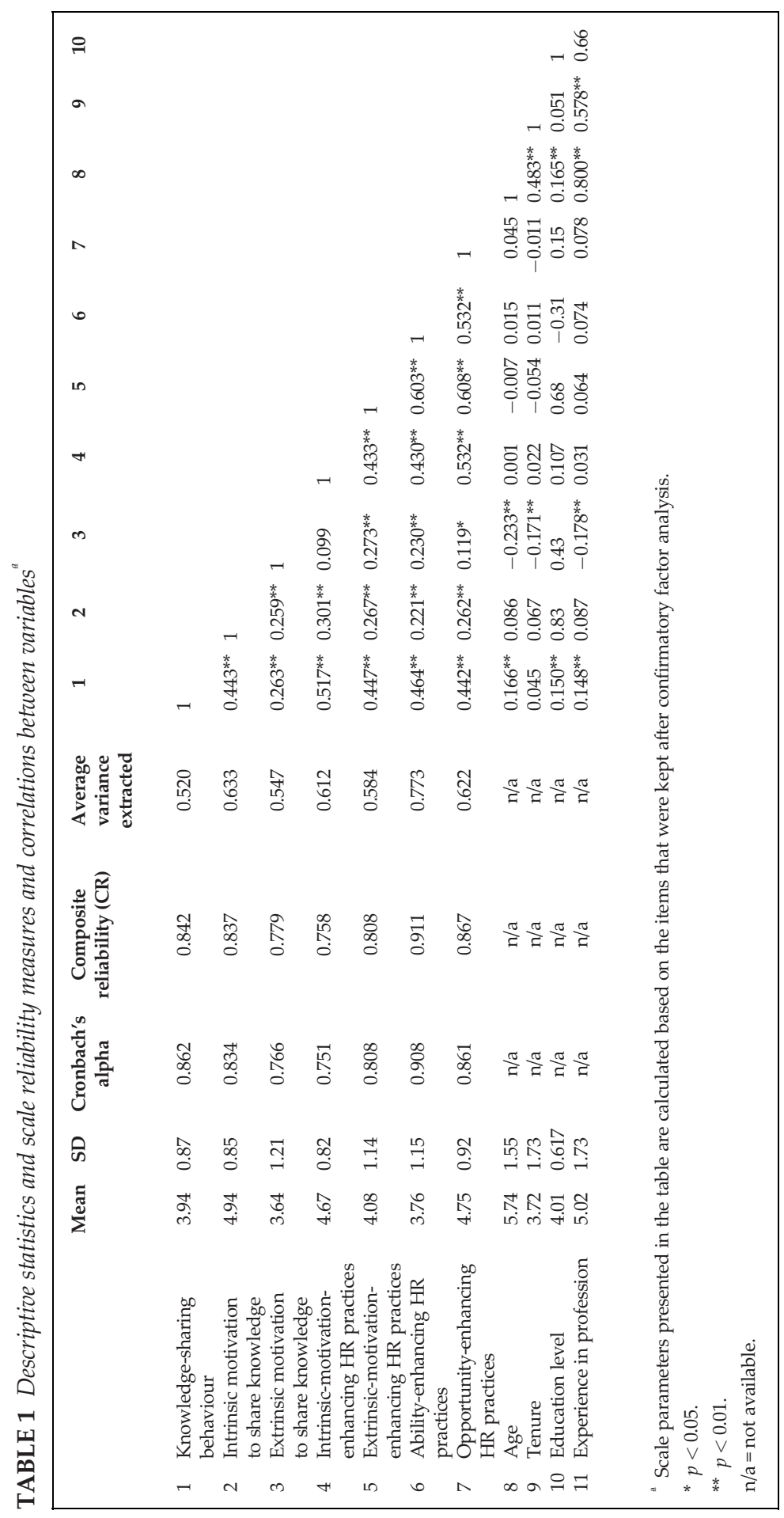


TABLE 2 Fit statistics for alternative structural models tested

\begin{tabular}{|c|c|c|c|c|c|c|c|c|}
\hline Models & $\chi^{2}$ & df & $\chi^{2} / \mathrm{df}$ & $\chi^{2} \operatorname{diff}$ & RMSEA & CFI & GFI & TLI \\
\hline Recommended fit indices & & & $<2$ & & $<0.05$ & $\geq 0.90$ & $\geq 0.90$ & $\geq 0.90$ \\
\hline $\begin{array}{l}\text { Mediation models } \\
\text { Model A }\end{array}$ & \multicolumn{7}{|c|}{ Mediation models } & 0.94 \\
\hline Model B & 487.526 & 260 & 1.875 & 20.342 & 0.052 & 0.944 & 0.896 & 0.936 \\
\hline Model C & 520.795 & 262 & 1.988 & 53.611 & 0.047 & 0.954 & 0.889 & 0.927 \\
\hline Model D & 444.153 & 258 & 1.722 & 23.031 & 0.047 & 0.954 & 0.904 & 0.947 \\
\hline \multicolumn{9}{|c|}{ Mediation-moderation models } \\
\hline Model E & 514.301 & 298 & 1.726 & 70.148 & 0.047 & 0.949 & 0.899 & 0.939 \\
\hline Model F & 476.866 & 278 & 1.715 & 32.713 & 0.047 & 0.951 & 0.902 & 0.943 \\
\hline \multicolumn{9}{|c|}{ Model fit of alternative mediated models is compared with the theoretical model A } \\
\hline \multicolumn{9}{|c|}{$\begin{array}{l}\text { Model A: theoretical model based on hypotheses - full mediation of rewards by extrinsic motivation, full mediation of } \\
\text { autonomy by intrinsic motivation and partial mediation of training by intrinsic motivation }\end{array}$} \\
\hline \multicolumn{9}{|c|}{$\begin{array}{l}\text { Model B: fully mediated model - only indirect links from rewards, autonomy and training to knowledge-sharing behavior, } \\
\text { mediated by two types of motivation }\end{array}$} \\
\hline \multicolumn{9}{|c|}{$\begin{array}{l}\text { Model C: non-mediated model - only direct links from all HR practices and two types of motivation to knowledge-sharing } \\
\text { behaviour }\end{array}$} \\
\hline \multicolumn{9}{|c|}{$\begin{array}{l}\text { Model D: partially mediated model: full mediation of rewards by extrinsic motivation and partial mediation of autonomy and } \\
\text { training by intrinsic motivation }\end{array}$} \\
\hline \multirow{2}{*}{\multicolumn{9}{|c|}{$\begin{array}{l}\text { Model fit of alternative moderated models is compared with the model } \mathrm{D} \text { as the mediated model that fits the data best } \\
\text { Model E: mediated-moderated model: model D with two interaction terms added (opportunity } \times \text { extrinsic motivation, } \\
\text { opportunity } \times \text { intrinsic motivation) }\end{array}$}} \\
\hline & & & & & & & & \\
\hline \multicolumn{9}{|c|}{$\begin{array}{l}\text { Model F: mediated-moderated model: model } \mathrm{D} \text { with one interaction term added (opportunity } \times \text { intrinsic motivation); } \\
\text { interaction term of (opportunity } \times \text { extrinsic motivation) is dropped as insignificant }\end{array}$} \\
\hline
\end{tabular}

showed good fit results (model A, Table 2): $\chi^{2}=467.184, \mathrm{df}=257, \chi^{2} / \mathrm{df}=1.818, \mathrm{RMSEA}=0.05$, goodness of fit index $(\mathrm{GFI})=0.901, \mathrm{TLI}=0.94, \mathrm{CFI}=0.948$.

As a comparison, we tested a fully mediated model, whereby we set only the indirect links between all the HR practices predicting only two types of motivation, which subsequently predicted knowledge-sharing behaviour (with no partial direct effects, model B, Table 2). We also tested an alternative model that included only direct relationships between all the independent variables (HR practices and individual motivations) and knowledge-sharing behaviour and no mediation at all (model C, Table 2). Neither of these models showed better fit statistics than our theoretical model, and both of them were significantly different from it. Furthermore, we tried different technically possible partial-mediation models, and one of them was slightly superior to our theoretical model (model D, Table 2: $\chi^{2}=444.153, \mathrm{df}=258$, $\left.\chi^{2} / \mathrm{df}=1.722, \mathrm{RMSEA}=0.047, \mathrm{GFI}=0.904, \mathrm{TLI}=0.947, \mathrm{CFI}=0.954\right)$ and was significantly different from it $\left(\chi^{2}\right.$ diff. $\left.=23.031, \mathrm{df}=1, p<0.001\right)$. In addition to our theoretical model, this model included a direct link from autonomy to knowledge-sharing behaviour, thus implying only partial mediation between intrinsic-motivation-enhancing HR practices and behaviour. Based on its statistical parameters, we chose model D as fitting our data best.

As the organisational control variables were so numerous, we were not able to use them in SEM analysis because of sample size limitations. To cross-check the SEM results, as well as to control for the possible nested effects of the organisation, we also ran ordinary least squares hierarchical regression to examine the mediation model, using the full set of control 
variables. ${ }^{3}$ While three organisational control variables were found to be statistically significant in intermediary regression models, they explained only 3.4 per cent and 3.5 per cent of the variance in the mediating variables; their impact became insignificant in the full research model. The results of the regression analysis confirmed the robustness of our findings and provided additional support for the mediating model.

\section{Opportunity-enhancing HR practices: testing the moderation hypotheses}

In order to test Hypothesis 4a and b, we followed the procedure suggested by Kline (2011). Two interaction terms between opportunity-enhancing practices and intrinsic and extrinsic motivation, respectively, were entered into the model (model E, Table 2). The interaction term between opportunity-enhancing practices and extrinsic motivation was not significantly related to knowledge-sharing behaviour, so we dropped this path, which resulted in a better model fit: $\chi^{2}=476.866, \mathrm{df}=278, \chi^{2} / \mathrm{df}=1.715$, RMSEA $=0.047$, GFI $=0.902$, TLI $=0.943$, $\mathrm{CFI}=0.951$ (model F, Table 2). The model with one interaction term was also significantly different from the best mediation model D $\left(\chi^{2}\right.$ diff. $=32.713$, df diff $\left.=21, p<0.05\right)$ and explained the larger percentage of variance in knowledge-sharing behaviour: 61.6 per cent compared with 60.1 per cent in model D.

The bold arrows in Figure 1 depict the significant paths of the best-fitting model (model F), the dotted arrows indicate the links that we did not hypothesise but discovered during the analysis, and thin grey arrows relate to our hypotheses that we did not confirm or were not able to test. The results of this model indicate that extrinsic-motivation-enhancing HR practices relate positively to extrinsic motivation to share knowledge $(\beta=0.318, p<0.001)$. Intrinsicmotivation-enhancing HR practices positively affect intrinsic motivation to share knowledge $(\beta=0.287, p<0.001)$. Both types of motivation in turn predict knowledge-sharing behaviour $(\beta=0.255, p<0.001$ and $\beta=0.161, p=0.001$ for intrinsic and extrinsic motivation, respectively). However, both ability-enhancing HR practices $(\beta=-0.069, p>0.05)$ and extrinsic-motivationenhancing HR practices $(\beta=0.164, p>0.05)$ are not related to intrinsic motivation to share knowledge. Ability-enhancing HR practices have a direct relationship with knowledge-sharing behaviour $(\beta=0.168, p<0.01)$. Intrinsic-motivation-enhancing HR practices also have a direct and significant relationship with knowledge-sharing behaviour $(\beta=0.420, p<0.001)$. The Sobel test additionally indicates that extrinsic motivation mediates the relationships between rewards and knowledge-sharing behaviour (Sobel $=2.66, p<0.05$ ) and intrinsic motivation - between autonomy and knowledge-sharing behaviour (Sobel=2.3, $p<0.05$ ). The additional test using the bootstrapping method also confirmed these results. Therefore, Hypotheses 1 and 2a were confirmed, Hypothesis $2 \mathrm{~b}$ could not be supported and Hypothesis $3 \mathrm{a}$ and $3 \mathrm{~b}$ could not be tested, as our measure of 'knowledge-sharing ability' did not work and we had to drop this variable out of the model.

In the final model, 61.6 per cent of the variance in employees' knowledge-sharing behaviour, 21.1 per cent of the variance in employees' intrinsic motivation to share knowledge and 10.1 per cent of the variance in the extrinsic motivation to share knowledge are explained. As predicted by our hypotheses, extrinsic motivation fully mediates the impact of rewards on knowledge sharing. In contrast to our hypotheses, intrinsic motivation only partially mediates the impact of autonomy on knowledge-sharing behaviour and does not mediate the effect of training on knowledge sharing, with training having a significant direct effect on employee behaviour.

The moderating effect of opportunity-enhancing HR practices was significant at $p<0.05$. To interpret and uncover the exact nature of this moderating effect, we conducted a multi-group 
FIGURE 1 Final structural model

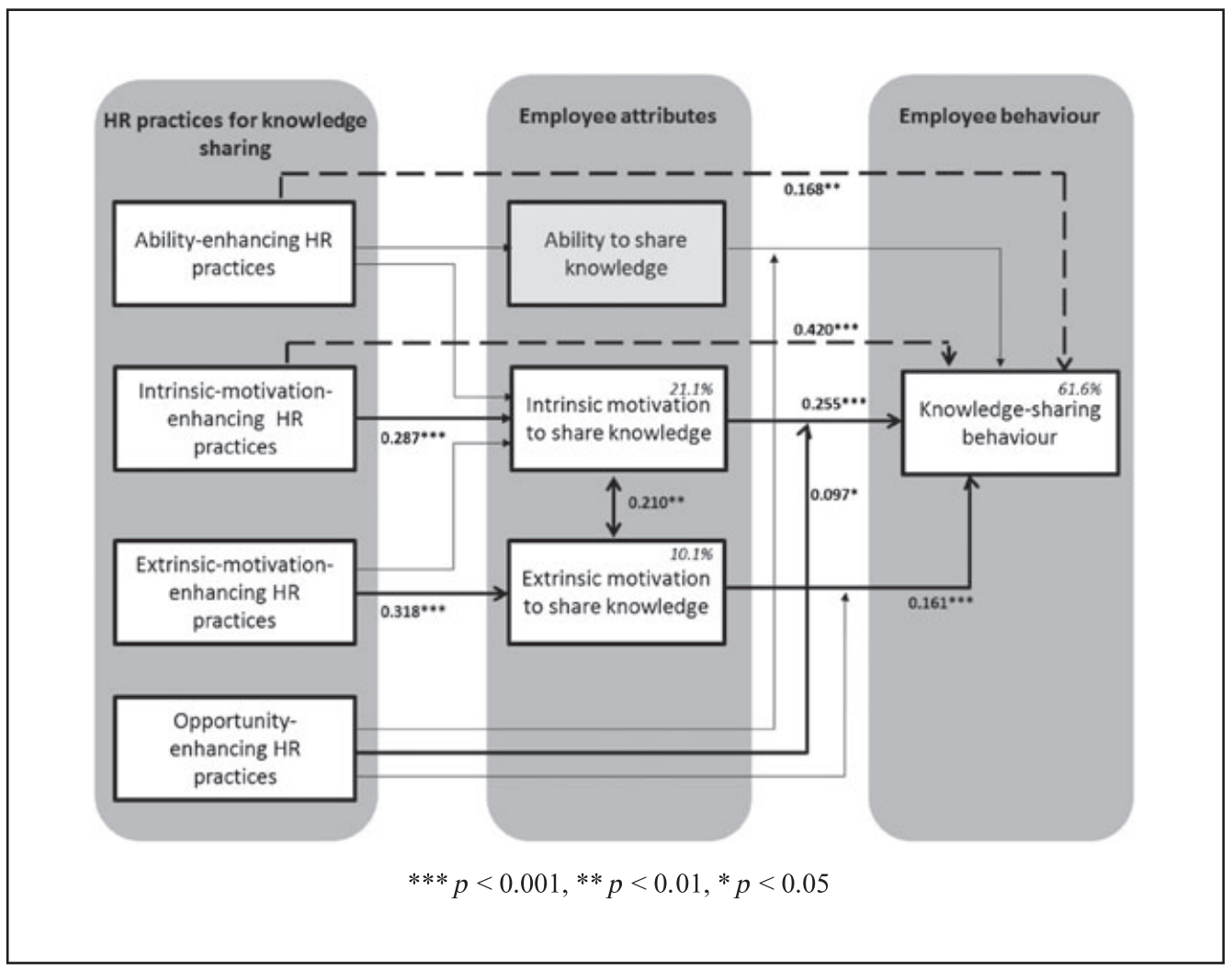

analysis to verify how exactly opportunity-enhancing HR practices moderate the causal relationships in the model. We performed a median split of the sample based on the standardised score of the 'opportunity-enhancing practices' variable and obtained two subsamples: one with a low level of opportunity-enhancing practices $(n=168)$ versus another with a high level of opportunity-enhancing practices $(n=161)$. A multi-group analysis was then conducted by comparing the separate regression estimates between two groups, and critical ratios for differences ( $>1.96$ criterion) were calculated to test the significance of difference between groups (Frazier et al., 2004). The results of these regressions for the subsamples are provided in Table 3.

The findings of the multi-group analysis are schematically visualised in Figure 2 (see next page). The opportunity-enhancing practices moderate the relationship between the two types of motivation and knowledge-sharing behaviour [the differences are statistically significant for the intrinsic motivation - knowledge-sharing behaviour relationship $\left(z=3.569^{* * *}\right)$ and for the extrinsic motivation - knowledge-sharing behaviour relationship $\left(z=-3.048^{* * *}\right)$ ]. At the low level of (perceived) opportunities, knowledge-sharing behaviour is significantly influenced by extrinsic motivation to share knowledge $(\beta=0.306, p<0.001)$ and intrinsic motivation has no significant relationship with knowledge sharing $(\beta=0.093, p>0.05)$. At the high level of 
TABLE 3 Regression coefficients for two subgroups (high and low level of perceived opportunities to share knowledge)

\begin{tabular}{|c|c|c|c|}
\hline Relationship & $\begin{array}{l}\text { Low level of perceived } \\
\text { opportunities }\end{array}$ & $\begin{array}{l}\text { High level of perceived } \\
\text { opportunities }\end{array}$ & $\begin{array}{l}\text { Difference between } \\
\text { the groups }\end{array}$ \\
\hline & Estimate & Estimate & $z$-score \\
\hline $\begin{array}{l}\text { Extrinsic-motivation-enhancing HR } \\
\text { practices } \rightarrow \text { extrinsic motivation }\end{array}$ & $0.159^{*}$ & $0.693^{* * *}$ & $3.259^{* * * *}$ \\
\hline Extrinsic motivation $\rightarrow$ intrinsic motivation & $0.31^{* *}$ & 0.101 & $-1.852^{*}$ \\
\hline Ability-enhancing practices $\rightarrow$ intrinsic motivation & -0.072 & 0.004 & 0.65 \\
\hline $\begin{array}{l}\text { Intrinsic-motivation-enhancing HR } \\
\text { practices } \rightarrow \text { intrinsic motivation }\end{array}$ & 0.301 & $0.22^{*}$ & -0.419 \\
\hline $\begin{array}{l}\text { Extrinsic-motivation-enhancing HR } \\
\text { practices } \rightarrow \text { intrinsic motivation }\end{array}$ & 0.151 & -0.044 & -1.342 \\
\hline $\begin{array}{l}\text { Intrinsic motivation } \rightarrow \text { knowledge- } \\
\text { sharing behaviour }\end{array}$ & 0.093 & $0.7^{* * *}$ & $3.569^{* * *}$ \\
\hline $\begin{array}{l}\text { Extrinsic motivation } \rightarrow \text { knowledge- } \\
\text { sharing behaviour }\end{array}$ & $0.306^{* * *}$ & -0.056 & $-3.048^{* * *}$ \\
\hline $\begin{array}{l}\text { Ability-enhancing practices } \rightarrow \text { knowledge- } \\
\text { sharing behaviour }\end{array}$ & 0.125 & $0.173^{*}$ & 0.393 \\
\hline $\begin{array}{l}\text { Intrinsic-motivation-enhancing HR } \\
\text { practices } \rightarrow \text { knowledge-sharing behaviour }\end{array}$ & $0.675^{* * *}$ & $0.385^{* *}$ & -1.282 \\
\hline $\begin{array}{l}\text { Extrinsic-motivation-enhancing HR } \\
\text { practices } \rightarrow \text { knowledge-sharing behaviour }\end{array}$ & 0.079 & 0.167 & 0.526 \\
\hline Tenure $\rightarrow$ knowledge-sharing behaviour & -0.01 & -0.033 & -0.433 \\
\hline Age $\rightarrow$ knowledge-sharing behaviour & 0.1 & 0.098 & -0.024 \\
\hline Education level $\rightarrow$ knowledge-sharing behaviour & 0.076 & 0.135 & 0.465 \\
\hline Experience $\rightarrow$ knowledge-sharing behaviour & 0.043 & -0.039 & -1.032 \\
\hline
\end{tabular}

FIGURE 2 The impact of two types of motivation on knowledge-sharing behaviour at a high and low level of opportunity

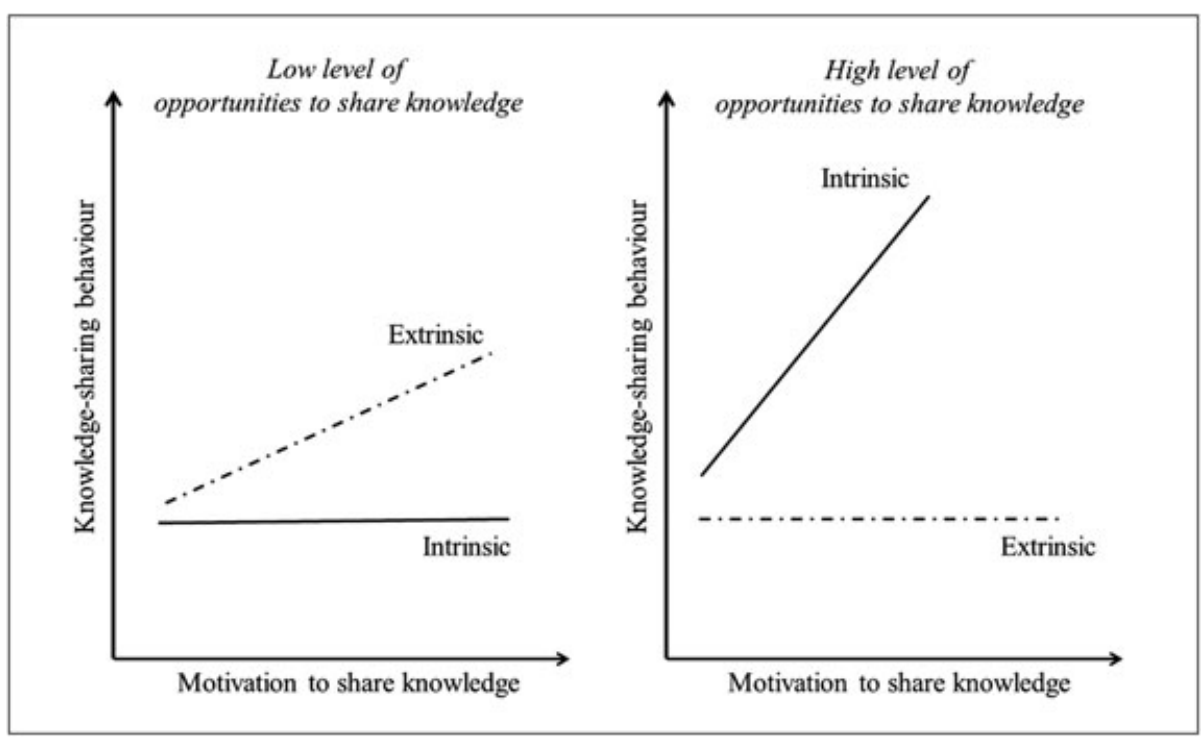


perceived opportunity practices, this configuration is reversed: intrinsic motivation to share knowledge significantly predicts knowledge-sharing behaviour with a dramatic increase in coefficient $(\beta=0.7, p<0.001)$ and extrinsic motivation to share knowledge drops to nonsignificance $(\beta=-0.056, p>0.05)$. The impact of intrinsic motivation on behaviour is more than twice that of the extrinsic, which is reflected in the slope of the stylised functions.

Therefore, we found partial support for Hypothesis $4 \mathrm{a}$ and $\mathrm{b}$ : opportunity-enhancing $\mathrm{HR}$ practices indeed moderate the relationship between motivation and knowledge-sharing behaviour but in different directions: these practices increase the impact of intrinsic motivation to share and offset the impact of extrinsic motivation to share.

\section{IMPLICATIONS FOR THEORY AND PRACTICE}

Our study makes several contributions to the theories of HRM and knowledge sharing. First, it demonstrates the importance of considering individual-level attributes as mediators in the relationship between HR practices and HR outcomes. Our model that includes both multiple HR practices, multiple individual attributes and the interplay between them explains 61 per cent of the variation in knowledge-sharing behaviour. This percentage is relatively high for behavioural studies in general and exceeds the findings of previous studies on knowledge-sharing behaviour in particular (e.g. 32 per cent in Foss et al., 2009 and 28 per cent in Reinholt et al., 2011). Therefore, our study empirically confirms the recent developments of both HRM (Boxall et al., 2011; Jiang et al., 2012) and knowledge governance theorists (Minbaeva et al., 2009) regarding the value added by a mediated model that includes individual-level attributes, giving a better explanation to the link between HR practices and HR outcomes.

Second, this study informs discussions about the influence of rewards on the motivation to share knowledge, related to possible crowding-out effects between intrinsic and extrinsic motivation to share knowledge (Osterloh and Frey, 2000). Recent reviews in the field of selfdetermination theory and work motivation demonstrate that the influence of intrinsic motivation on behaviour is not necessarily crowded out by rewards as such but rather depends on multiple organisational conditions, such as the type of rewards offered, the type of performance rewarded, organisational climate or job design characteristics (e.g. Gagne and Deci, 2005; Cerasoli et al., 2014). However, the studies applying self-determination theory to the particular case of knowledge-sharing behaviour have not addressed such potentially moderating conditions. At the same time, including potential moderators might explain why the research on how rewards for knowledge sharing interact with intrinsic motivation to share knowledge has so far been inconclusive and ambiguous (e.g. Bock et al., 2005; Cabrera et al., 2006; Liu and Liu, 2011). Our study extends the arguments on the importance of the organisational conditions for motivation (Gagne and Deci, 2005; Cerasoli et al., 2014) to the case of knowledge-sharing behaviour by identifying another important moderating condition, which acts as a catalyst for either type of motivation to share knowledge to be activated. Specifically, our findings suggest that the type of motivation that is activated depends on the perceived level of the opportunities to share knowledge provided by the organisation. In a favourable situation, when many opportunities to share knowledge exist, the intrinsic motivation to share is the key predictor of knowledge-sharing behaviour, and extrinsic motivation has no effect on the behaviour. When opportunities are lacking, extrinsic motivation to share becomes critical, while intrinsic motivation does not matter 
anymore for knowledge-sharing behaviour. Therefore, the two types of motivation can be thought of as 'sets of playing cards' that an individual owns and puts on the table depending on the game being played. This finding is also important as it demonstrates that there are conditions under which the intrinsic motivation to share may be high but does not lead to knowledge-sharing behaviour after all, in contrast with what is implied by Foss et al. (2015).

Moreover, our study confirms that it is important to distinguish between external stimuli and extrinsic motivation as different constructs and recognise that extrinsic motivation is an important mediator between rewards as stimuli and the resulting behaviour. This finding is important because it demonstrates that external rewards for knowledge sharing per se do not have a detrimental impact on knowledge-sharing attitudes and behaviour. Yet, the effect of extrinsic-motivation-enhancing HR practices depends on the availability of other HR practices. This finding leads us to our next contribution.

We extend recent discussions on the differentiated effects of various HR practices (Jiang et al., 2012) and potential interactions and controversies within HR systems in general (e.g. Kepes and Delery, 2007; Boxall et al., 2011) and HR systems for knowledge sharing in particular (Minbaeva et al., 2009). According to our study, HR practices that provide opportunities for sharing knowledge set off the effect of HR practices aimed at boosting extrinsic motivation to share. Extrinsic-motivation-enhancing HR practices still have a significant positive effect on extrinsic motivation, but the latter fully mediates their impact on knowledge-sharing behaviour. When several opportunities for sharing are available, extrinsic motivation becomes insignificant. This means that in certain conditions, rewards for increasing extrinsic motivation may actually be pointless - they increase motivation, which does not ultimately influence behaviour. Thus, our study highlights that understanding mediating mechanisms is critical not only for better explaining the link between HR practices and employee behaviour but also for understanding the interaction mechanisms between different HR practices. On the one hand, this finding argues against the common practice of studying HR systems as additive sets of HR practices (Combs et al., 2006) and shows the differentiated effect that various practices may have (e.g. Lepak et al., 2006; Jiang et al., 2012). However, another issue makes this finding even more interesting. The common assumption in the literature is that HR practices may conflict or be counterproductive when they are not aligned with each other - for example, when an organisation promotes teamwork but has only individual achievement-based compensation (Boxall et al., 2011). On the contrary, HR practices that are well-aligned with each other and follow clear strategic goals are believed to show a particularly powerful joint effect (Bowen and Ostroff, 2004; Minbaeva, 2013; Foss et al., 2015). Our study warns that the combinatory effect of even well-aligned HR practices, that is, of those that are all aimed to enhance knowledge sharing, is not always as good as expected. In line with the theoretical considerations of Minbaeva et al. (2009), our findings demonstrate that having more HR practices to support knowledge sharing does not always pay off.

These findings have an important practical implication. HR practice 'common sense' frequently leads managers to begin their knowledge-sharing-enhancing HR efforts by offering rewards for knowledge sharing (Bartol and Srivastava, 2002). Our findings suggest that this practice may lead to spending money in vain if organisations provide both rewards and opportunities for sharing at the same time. Our study suggests that managers willing to enhance knowledge sharing could choose one of these approaches. Moreover, as rewards have a weaker effect on employee behaviour than providing rich opportunities for knowledge sharing, 
organisations would be more efficient in their efforts to promote knowledge sharing if they focused on the opportunities rather than on rewards. These findings are particularly relevant for situations where organisational resources are limited and HR managers need to make choices between HR practices and decide which to implement first in order to enhance knowledge sharing.

Interpreting our findings, it is important to acknowledge that our data were collected in the specific setting of secondary schools - a particular context that might differ from many business settings commonly studied in HRM research. The HR practices exercised in schools and their impact on the knowledge-sharing behaviour of teachers might be influenced by the peculiarities of the professional and institutional context in which they are embedded. For example, in contrast to many jobs in business, the teaching profession traditionally provides quite a high level of autonomy, and individuals entering schools as a workplace may perceive it as natural. For this reason, the positive effect of the autonomy on intrinsic motivation to share knowledge that we found in our study might be relatively lower compared with business organisations. Another peculiarity may relate to non-collaborative, independent work arrangements traditional to Russian secondary schools. Natural opportunities to share knowledge, inherent to the settings where the work is more team-based or interdependent, are less present in the context of Russian schools where teachers mostly work individually. Therefore, when the opportunities to share knowledge are purposefully introduced by management, they might have a stronger effect on knowledge-sharing behaviour than similar practices would have had in a different setting. Yet one more possible distinctive feature of our data is the national educational system it is embedded in, where teachers have traditionally been very low-paid (Derkachev, 2015), and therefore, extrinsic rewards might be a stronger motivator for Russian teachers than for their peers in other countries or employees in the corporate world. Finally, the teaching profession is also known to attract a specific type of individual, often driven by an inner passion for teaching (Watt et al., 2012). This may explain the high level of intrinsic motivation to share knowledge in our study that might differ from possibly lower levels of intrinsic motivation to share knowledge in other contexts. These speculations suggest that our results should be interpreted with a careful consideration of the context in mind (Sergeeva and Andreeva, 2015), in line with recent calls for HRM research to be more sensitive to the objectives that HR practices are trying to achieve and in what kind of environment (Lepak et al., 2006).

\section{Limitations and avenues for further research}

As with any research, this study is not without limitations, which should be taken into account when interpreting the results. First, the cross-sectional nature of the data limits the scope of the conclusions regarding causal relationships between the variables in the model. Our respondents reported their perceptions of current HR practices and present levels of motivation and knowledge-sharing behaviour simultaneously. Although our analysis is well grounded in the existing theory on knowledge sharing, alternative causal links may also exist. For example, employees might be more intrinsically motivated to share knowledge because of their previous activity in knowledge sharing and the satisfaction it brought. Future research would benefit from testing the proposed model with a longitudinal study, by tracking the dynamics of the employee attitudes and behaviours after the implementation of the HR practices.

Second, an important element of the theoretical model, employee ability to share knowledge, is missing in our empirical analysis, and our study could not directly assess the mediating effect of the individual ability to share knowledge because of the cross-loadings of our scale items. 
We interpret this finding as a problem with the operationalisation of the 'knowledge-sharing ability' construct. Although some literature has discussed how we can capture the individual ability to share knowledge (Hinds and Pfeffer, 2003; Jackson et al., 2006; Gavrilova and Andreeva, 2012), precise measures are still lacking. According to our results, measuring it through knowledge-sharing self-efficacy also does not appear to be the right approach. However, it cannot be concluded either that the mediating mechanisms between abilityenhancing HR practices and knowledge-sharing behaviour are absent or that opportunityenhancing HR practices do not moderate these mechanisms. Moreover, our findings pinpoint the need for a different operationalisation of knowledge-sharing ability, as the operationalisation of this theoretical construct through knowledge-sharing self-efficacy did not work. Future studies should address this issue, possibly taking a more inductive approach to develop a more precise concept and measures of the ability of employees to share knowledge.

\section{CONCLUSION}

In spite of the limitations, this study is an important contribution to the theory and practice of knowledge-based HRM. It uncovers how HR practices influence employee knowledge-sharing behaviour by examining the mediating role of individual-level attributes in this relationship and by considering the interplay between HR practices. Our study revealed that individual extrinsic motivation to share knowledge fully mediates the impact of rewards on knowledgesharing behaviour. Intrinsic motivation acts as a partial mediator between autonomous job design and knowledge sharing. However, the identified mediating mechanisms are also contingent on the level of opportunity to share knowledge, depending on which one of the motivation types is activated and which is suppressed. By revealing these effects and their moderating conditions, the study makes an important contribution to the knowledge-based perspective of HRM research, highlighting how certain combinations of HR practices might be costly and counterproductive for knowledge-sharing behaviour because of the differences in their mediating mechanisms in the HRM-knowledge-sharing behaviour link.

\section{Acknowledgements}

We would like to thank Peter Boxall, James Guthrie, Jaap Paauwe and two anonymous reviewers of Human Resource Management Journal for their constructive feedback on previous drafts of this article. Tatiana Andreeva would like to acknowledge financial support from Russian Science Foundation grant (project No. 15-18-30048).

\section{$\underline{\text { Notes }}$}

1. The authors can provide the details of this analysis upon request.

2. More details on the fit statistics of the comparison of these and other alternative measurement models can be provided by authors upon request

3. The results are available from authors upon request.

\section{REFERENCES}

Bandura, A. (1977). 'Self-efficacy: toward a unifying theory of behavioral change'. Psychological Review, 84: 2, 191-215. 
Baron, R.M. and Kenny, D.A. (1986). 'The moderator-mediator variable distinction in social psychological research: conceptual, strategic, and statistical considerations'. Journal of Personality and Social Psychology, 51: 6, 1173-1182.

Bartol, K.M. and Srivastava, A. (2002). 'Encouraging knowledge sharing: the role of organizational reward systems'. Journal of Leadership \& Organizational Studies, 9: 1, 64-76.

Blau (1964). Exchange and Power in Social Life, New York: Wiley.

Bock, G.W., Zmud, R.W., Kim, Y.G. and Lee, J.N. (2005). 'Behavioral intention formation in knowledge sharing: examining the roles of extrinsic motivators, social-psychological forces, and organizational climate'. MIS Quarterly, 29: 1, 87-111.

Bowen, D.E. and Ostroff, C. (2004). 'Understanding HRM-firm performance linkages: the role of the "strength" of the HRM system'. Academy of Management Review, 29: 2, 203-221.

Boxall, P., Ang, S.H. and Bartram, T. (2011). 'Analysing the "black box" of HRM: uncovering HR goals, mediators, and outcomes in a standardized service environment'. Journal of Management Studies, 48: 7, 1504-1532.

Cabrera, A., Collins, W.C. and Salgado, J.F. (2006). 'Determinants of individual engagement in knowledge sharing'. International Journal of Human Resource Management, 17: 2, 245-264.

Cerasoli, C.P., Nicklin, J.M. and Ford, M.T. (2014). 'Intrinsic motivation and extrinsic incentives jointly predict performance: a 40-year meta-analysis'. Psychological Bulletin, 140: 4, 980-1008.

Chang, Y.Y., Gong, Y. and Peng, M.W. (2012). 'Expatriate knowledge transfer, subsidiary absorptive capacity, and subsidiary performance'. Academy of Management Journal, 55: 4, 927-948.

Chiu, C.M., Hsu, M.H. and Wang, E.T. (2006). 'Understanding knowledge sharing in virtual communities: an integration of social capital and social cognitive theories'. Decision Support Systems, 42: 3, $1872-1888$.

Cohen, W.M. and Levinthal, D.A. (1990). 'Absorptive capacity: a new perspective on learning and innovation'. Administrative Science Quarterly, 35: 1, 128-152.

Combs, J., Liu, Y., Hall, A. and Ketchen, D. (2006). 'How much do high-performance work practices matter? A meta-analysis of their effects on organizational performance'. Personnel Psychology, 59, 501-528.

Constant, D., Kiesler, S. and Sproull, L. (1994). 'What's mine is ours, or is it? A study of attitudes about information sharing'. Information Systems Research, 5: 4, 400-421.

Deci, E.L. and Ryan, R.M. (2004). Handbook of Self-determination Research, Rochester, NY: University of Rochester Press.

Derkachev, P.V. (2015). Where is a teacher happy in Russia? Indicators of teachers' salaries. Working paper provided by National Research University Higher School of Economics in its series HSE Working papers: WP BRP 28/PA/2015. https://ideas.repec.org/p/hig/wpaper/28-pa-2015.html

Dixon, N.M. (2000). Common Knowledge: How Companies Thrive by Sharing What They Know, Boston, MA: Harvard Business Press.

Foss, N.J. (2007). 'The emerging knowledge governance approach: challenges and characteristics'. Organization, 14: 1, 29-52.

Foss, N.J., Minbaeva, D.B., Pedersen, T. and Reinholt, M. (2009). 'Encouraging knowledge sharing among employees: how job design matters'. Human Resource Management, 48: 6, 871-893.

Foss, N.J., Husted, K. and Michailova, S. (2010). 'Governing knowledge sharing in organizations: levels of analysis, governance mechanisms, and research directions'. Journal of Management Studies, 47: 3, 455-482.

Foss, N.J., Pedersen, T., Reinholt Fosgaard, M. and Stea, D. (2015). 'Why complementary HRM practices impact performance: the case of rewards, job design, and work climate in a knowledgesharing context'. Human Resource Management, 54: 6, 955-976.

Frazier, P.A., Tix, A.P. and Barron, K.E. (2004). 'Testing moderator and mediator effects in counseling psychology research'. Journal of Counseling Psychology, 51: 1, 115-134.

Fullan, M. (2002). 'The role of leadership in the promotion of knowledge management in schools'. Teachers and Teaching: Theory and Practice, 8: 3, 409-419.

Gagné, M. (2009). 'A model of knowledge-sharing motivation'. Human Resource Management, 48: 4, 571-589.

Gagné, M. and Deci, E.L. (2005). 'Self-determination theory and work motivation'. Journal of Organizational Behavior, 26: 4, 331-362. 
Gardner, T.M., Wright, P.M. and Moynihan, L.M. (2011). 'The impact of motivation, empowerment, and skills-enhancing practices on aggregate voluntary turnover: the mediating effect of collective affective commitment'. Personnel Psychology, 64: 2, 315-350.

Gavrilova, T. and Andreeva, T. (2012). 'Knowledge elicitation techniques in a knowledge management context'. Journal of Knowledge Management, 16: 4, 523-537.

Grant, R.M. (1996). 'Toward a knowledge-based theory of the firm'. Strategic Management Journal, 17: S2, 109-122.

Hackman, J.R. and Oldham, G.R. (1975). 'Development of the job diagnostic survey'. Journal of Applied Psychology, 60: 2, 159-170.

Hackman, J.R. and Oldham, G.R. (1976). 'Motivation through the design of work: test of a theory'. Organizational Behavior and Human Performance, 16: 2, 250-279.

Hargreaves, A. and Fullan, M. (2012). Professional Capital: Transforming Teaching in Every School, New York: Teachers College Press.

Harman, H.H. (1976). Modern Factor Analysis, Chicago, IL: University of Chicago Press.

Hinds, P.J. and Pfeffer, J. (2003). 'Why organizations don't "know what they know": cognitive and motivational factors affecting the transfer of expertise', in M. Ackerman, V. Pipek and V. Wulf (eds), Sharing Expertise: Beyond Knowledge Management, Cambridge, MA: MIT Press.

Hinds, P.J., Patterson, M. and Pfeffer, J. (2001). 'Bothered by abstraction: the effect of expertise on knowledge transfer and subsequent novice performance'. Journal of Applied Psychology, 86: 6, 1232-1243.

Hsu, M.H., Ju, T.L., Yen, C.H. and Chang, C.M. (2007). 'Knowledge sharing behavior in virtual communities: the relationship between trust, self-efficacy, and outcome expectations'. International Journal of Human-Computer Studies, 65: 2, 153-169.

Hu, L.T. and Bentler, P.M. (1999). 'Cutoff criteria for fit indexes in covariance structure analysis: conventional criteria versus new alternatives'. Structural Equation Modeling: a Multidisciplinary Journal, 6: 1, 1-55.

Jackson, S.E., Chuang, C.-H., Harden, E.E. and Jiang, Y. (2006). 'Toward developing human resource management systems for knowledge-intensive teamwork', in J.J. Martocchio (ed.), Research in Personnel and Human Resources Management, Vol. 25, Bingley: Emerald Group Publishing.

Jiang, K., Lepak, D.P., Hu, J. and Baer, J.C. (2012). 'How does human resource management influence organizational outcomes? A meta-analytic investigation of mediating mechanisms'. Academy of Management Journal, 55: 6, 1264-1294.

Kehoe, R.R. and Wright, P.M. (2013). 'The impact of high-performance human resource practices on employees' attitudes and behaviors'. Journal of Management, 39: 2, 366-391.

Kepes, S. and Delery, J.E. (2007). 'HRM systems and the problem of internal fit', in P. Boxall, J. Purcell and P. Wright (eds), The Oxford Handbook of Human Resource Management, New York: Oxford University Press.

Kianto, A., Andreeva, T. and Shi, X. (2011). 'Knowledge management across the globe - an international survey of KM awareness, spending, practices and performance', in F. Lehner and K. Bredl (eds), Proceedings of the 12th European Conference on Knowledge Management, Reading: Academic Publishing International, pp. 514-523.

Kline, R.B. (2011). Principles and Practice of Structural Equation Modeling, 3rd edn, New York: The Guilford Press.

Kuvaas, B., Buch, R. and Dysvik, A. (2012). 'Perceived training intensity and knowledge sharing: sharing for intrinsic and prosocial reasons'. Human Resource Management, 51: 2, 167-187.

Lepak, D.P., Liao, H., Chung, Y. and Harden, E.E. (2006). 'A conceptual review of human resource management systems in strategic human resource management research'. Research in Personnel and Human Resources Management, 25: 1, 217-271.

Liao, H., Toya, K., Lepak, D.P. and Hong, Y. (2009). ‘Do they see eye to eye? Management and employee perspectives of high-performance work systems and influence processes on service quality'. Journal of Applied Psychology, 94: 2, 371-391.

Lin, H.F. (2007). 'Effects of extrinsic and intrinsic motivation on employee knowledge sharing intentions'. Journal of Information Science, 33: 2, 135-149.

Liu, N.C. and Liu, M.S. (2011). 'Human resource practices and individual knowledge-sharing behavioran empirical study for Taiwanese R\&D professionals'. International Journal of Human Resource Management, 22: 4, 981-997. 
Minbaeva, D.B. (2013). 'Strategic HRM in building micro-foundations of organizational knowledge-based performance'. Human Resource Management Review, 23, 378-390.

Minbaeva, D., Foss, N. and Snell, S. (2009). 'Bringing the knowledge perspective into HRM'. Human Resource Management, 48: 4, 477-483.

Minbaeva, D.B., Mäkelä, K. and Rabbiosi, L. (2012). 'Linking HRM and knowledge transfer via individuallevel mechanisms'. Human Resource Management, 51: 3, 387-405.

Nahapiet, J. and Ghoshal, S. (1998). 'Social capital, intellectual capital, and the organizational advantage'. Academy of Management Review, 23: 2, 242-266.

Osterloh, M. and Frey, B.S. (2000). 'Motivation, knowledge transfer, and organizational forms'. Organization Science, 11: 5, 538-550.

Parker, S.K. (1998). 'Enhancing role breadth self-efficacy: the roles of job enrichment and other organizational interventions'. Journal of Applied Psychology, 83: 6, 835-852.

Podsakoff, P.M., MacKenzie, S.B., Lee, J.Y. and Podsakoff, N.P. (2003). 'Common method biases in behavioral research: a critical review of the literature and recommended remedies'. Journal of Applied Psychology, 88: 5, 879-903.

Reinholt, M., Pedersen, T. and Foss, N.J. (2011). 'Why a central network position isn't enough: the role of motivation and ability for knowledge sharing in employee networks'. Academy of Management Journal, 54: 6, 1277-1297.

Ryan, R.M. and Connell, J.P. (1989). 'Perceived locus of causality and internalization: examining reasons for acting in two domains'. Journal of Personality and Social Psychology, 57: 5, 749-761.

Ryan, R.M. and Deci, E.L. (2000). 'Intrinsic and extrinsic motivations: classic definitions and new directions'. Contemporary Educational Psychology, 25: 1, 54-67.

Sergeeva, A. and Andreeva, T. (2015). 'Knowledge sharing: bringing the context back in'. Journal of Management Inquiry, DOI: 10.1177/1056492615618271.

Siemsen, E., Roth, A.V. and Balasubramanian, S. (2008). 'How motivation, opportunity, and ability drive knowledge sharing: the constraining-factor model'. Journal of Operations Management, 26: 3, 426-445.

Starbuck, W.H. (1992). 'Learning by knowledge-intensive firms'. Journal of Management Studies, 29: $6,713-740$.

Swart, J. and Kinnie, N. (2013). 'Managing multidimensional knowledge assets: HR configurations in professional service firms'. Human Resource Management Journal, 23: 2, 160-179.

Takeuchi, R., Lepak, D.P., Heli, W. and Takeuchi, K. (2007). 'An empirical examination of the mechanisms mediating between high-performance work systems and the performance of Japanese organizations'. Journal of Applied Psychology, 92: 4, 1069-1083.

Tannenbaum, S.I., Mathieu, J.E., Salas, E. and Cannon-Bowers, J.A. (1991). 'Meeting trainees' expectations: the influence of training fulfillment on the development of commitment, self-efficacy, and motivation'. Journal of Applied Psychology, 76: 6, 759-769.

Vroom, V.H. (1994). Work and Motivation, San Francisco, CA: Jossey-Bass.

Wang, S. and Noe, R.A. (2010). 'Knowledge sharing: a review and directions for future research'. Human Resource Management Review, 20: 2, 115-131.

Watt, H.M., Richardson, P.W., Klusmann, U., Kunter, M., Beyer, B., Trautwein, U. and Baumert, J. (2012). 'Motivations for choosing teaching as a career: an international comparison using the FIT-Choice scale'. Teaching and Teacher Education, 28: 6, 791-805.

Wu, W.L., Hsu, B.F. and Yeh, R.S. (2007). 'Fostering the determinants of knowledge transfer: a team-level analysis'. Journal of Information Science, 33: 3, 326-339.

Youndt, M.A. and Snell, S.A. (2004). 'Human resource configurations, intellectual capital, and organizational performance'. Journal of Managerial Issues, 16: 3, 337-360. 


\section{APPENDIX}

TABLE A1 Study constructs and measurement scales

\section{Constructs and items}

\section{Knowledge-sharing behaviour}

I actively participate in knowledge-sharing activities in our school

When discussing a complicated issue, I am usually

involved in the subsequent interactions

I usually spend a lot of time sharing knowledge in our school

I participate in discussing all kinds of day-to-day questions, not only in my own area of studies*

Being a member of our school, I usually actively share my knowledge with others

\section{Intrinsic motivation to share knowledge}

I like sharing knowledge

I think sharing knowledge is an important part of my job

I find it personally satisfying

Extrinsic motivation to share knowledge

I share knowledge because I want my supervisor to praise me

I share knowledge because I want my colleagues to praise $\mathrm{me}^{*}$

I share knowledge because I want get a reward

I share knowledge because it might help me get promoted

Extrinsic-motivation-enhancing HR practices

Our school specifically rewards knowledge sharing with monetary incentives.

Our school specifically rewards knowledge sharing with non-monetary incentives.

In our school, knowledge sharing is a component in employees' performance evaluation

\section{Intrinsic-motivation-enhancing HR practices}

To what extent is your job characterized by the following:

The freedom to carry out my job the way I want to

The opportunity for independent initiative

High level of variety in my job

\section{Opportunity-enhancing HR practices}

The school holds birthday parties, trips, and other hours together activities that promote friendship among colleagues

The school invites high-performance employees to share their knowledge with others in meetings

The school invites employees who have just acquired new knowledge from outside sources

to share what they have learned with others.

The school holds regular meetings where olleagues can share successful experiences or resolve work problems.

The school allows teachers to consult their colleagues on problems during work time*

There are annual conferences concerning certain products that require in-depth discussion among colleagues in our school*

There are rest rooms available where teachers can talk to each other and share experience in our school*

The company assigns every new employee a senior employee and coaching to help him/?her during orientation**

The company has mentoring programs in which employees can receive their mentor's help at any time**

\section{Ability-enhancing HR practices}

In our school there are trainings to develop interpersonal communication skills

In our school there are trainings for teamwork skills

The school provides trainings to develop skills of self-reflection and knowledge externalisation

* Items were excluded from the scales during CFA.

** These items were excluded from the scale as irrelevant to the study context based on the results of the qualitative research, which revealed that these practices are not exercised in the schools we studied. 